GrÉGOIRe, Ch. (1951). J. gen. Microbiol. 5, 121-123.

\title{
Virus-like Bodies in the Blood of the House Gricket
}

\author{
By Ch. GRÉGOIRE \\ Laboratoire biochimique et biologique de microscopie électronique, \\ University of Liége
}

SUMMARY : Virus-like structures were accidentally discovered by electron-microscopy in the blood of adult house crickets which had no external signs of disease.

During an examination by electron-microscopy of haemolymph clots of insects, granular bodies were found by chance in preparations from the house cricket (Gryllulus domesticus). These structures are briefly described in the following note.

\section{MATERIAL AND METHODS}

The preparations consisted of thin films of haemolymph from the antennae or legs of adult specimens of apparently disease-free crickets. A small drop of haemolymph was spread between slide and cover-slip previously coated with $0.15 \%(w / v)$ formvar solution in ethylene dichloride or $0.5 \%(w / v)$ parlodion in amyl acetate, and fixed by immersion in a $2 \%(\mathrm{w} / \mathrm{v})$ solution of osmic acid. Small areas of plastic film supporting the blood preparations were then cut from the surrounding film with a pair of sharp scissors, peeled away from the glass and transferred under water on to standard stainless steel screens for electron-microscopy. The covered screens were then lifted from the water, drained, dried and examined or photographed with an R.C.A., type E.M.U. electron microscope.

Twenty-five adult crickets belonging to the breeding stock of the Department of Biochemistry were used and about two hundred screens examined. As the findings were made after the insect specimens had been discarded, no anatomical study of the tissues could be performed.

\section{RESULTS}

On examining these preparations under the electron microscope, minute granules, either in high concentration (fig. 1, see Pl. 1) or scattered at random (figs. 3-5, 10 and 11) were found. Most of them appeared to be oval in shape with a definite internal organization, consisting of a central dense rod-shaped structure, surrounded by a relatively transparent area (figs. 2, 15). Circular areas of high density were occasionally visible either at both ends of the rod (figs. 3, 4, 10 and 11) or aligned within it (fig. 16). Less frequently, forms were found in which the central rod was not visible (figs. 6, 11), or only faintly outlined (figs. 7, 9, 10,12 and 13), with two spherical polar zones of higher density distinctly apparent. These dense polar areas were sometimes the only internal structures seen in the egg-shaped transparent body (fig. 12). As seen in fig. 14, the dense internal rod was not always located at the centre of the granule: the clear area then appeared on one side of it. This fact, together with 
large variations in diameter of the clear oval area, suggests that the latter structure may have some plasticity around the relatively more rigid central rod-like structure. Figs. 8 and 11 show that this rod may, however, bend, giving the granule a more spherical shape. From measurements on electron micrographs of three hundred internal rods, their average size appeared to be approximately $223 \times 57 \mathrm{~m} \mu$.

These bodies were found in the haemolymph of eight out of twenty-five adult crickets. The frequency of occurrence of these structures was probably higher, but owing to their scarcity in some preparations, they might have been overlooked in the preparations from the other insects.

Most of the haemocytes visible in the films of coagulated haemolymph were disintegrated and their cytoplasmic constituents (granules, mitochondria, endoplasmic particles) were distributed in the surrounding plasma coagulum. The presence of virus-like bodies scattered among the cytoplasmic structures suggests that they, too, were originally inside the haemocytes, although they appear free in the plates. The thickness of the remaining intact haemocytes did not allow critical observation of the minute structures within their cytoplasm.

\section{DISCUSSION}

Granules showing some similarity of structure with those described in the present note have been recognized as viruses and etiological agents of granulosis in insects (Paillot, 1934) and demonstrated by means of the electron microscope by Bergold (1948), Steinhaus, Hughes \& Wasser (1949), and Steinhaus \& Thompson (1949). Bergold (1948) observed in the cytoplasm of blood cells of infected caterpillars of the pine shoot roller, Cacoecia murinana, $\mathrm{Hb}$., vesicular structures containing large numbers of egg-shaped particles having a size of $360 \times 230 \mathrm{~m} \mu$. On treatment with sodium carbonate solution, these particles (capsules) released rod-like structures, $262 \times 50 \cdot 6 \mathrm{~m} \mu$. in size, and resembling the virus particles found in polyhedroses.

Under the electron microscope Steinhaus et al. (1949) observed opaque oval granules with no significant internal structure, and having a size of approximately $250 \times 400 \mathrm{~m} \mu$. in suspensions of infected tissues of the variegated cutworm, Peridroma margaritosa (Haw). In preparations of fat tissue from infected cutworms suspended in sodium carbonate, the granules lose some of their dense aspect, and a relatively clear rod-shaped area or cavity may be seen more or less centrally located along the long axis of the granule. Rod-shaped particles of about the same dimensions as the cavities and representing probably the virus itself can be seen lying among the granules. Similar ovoid granules, of about $350 \times 500 \mathrm{~m} \mu$. in size, and enclosing rod-shaped virus particles, were recently demonstrated by Steinhaus \& Thompson (1949) in diseased tissues of the Buckeye caterpillar, Junonia coenia.

There are important differences between the morphological features of the granules described in the present note and those studied by Bergold and by Steinhaus and his co-workers. The granules described by these workers are considerably larger, and consist of a dense solid substance, impermeable to electrons, in which the virus particles and other internal structures can only 

Journal of General Microbiology, Vol. 5, No. 1
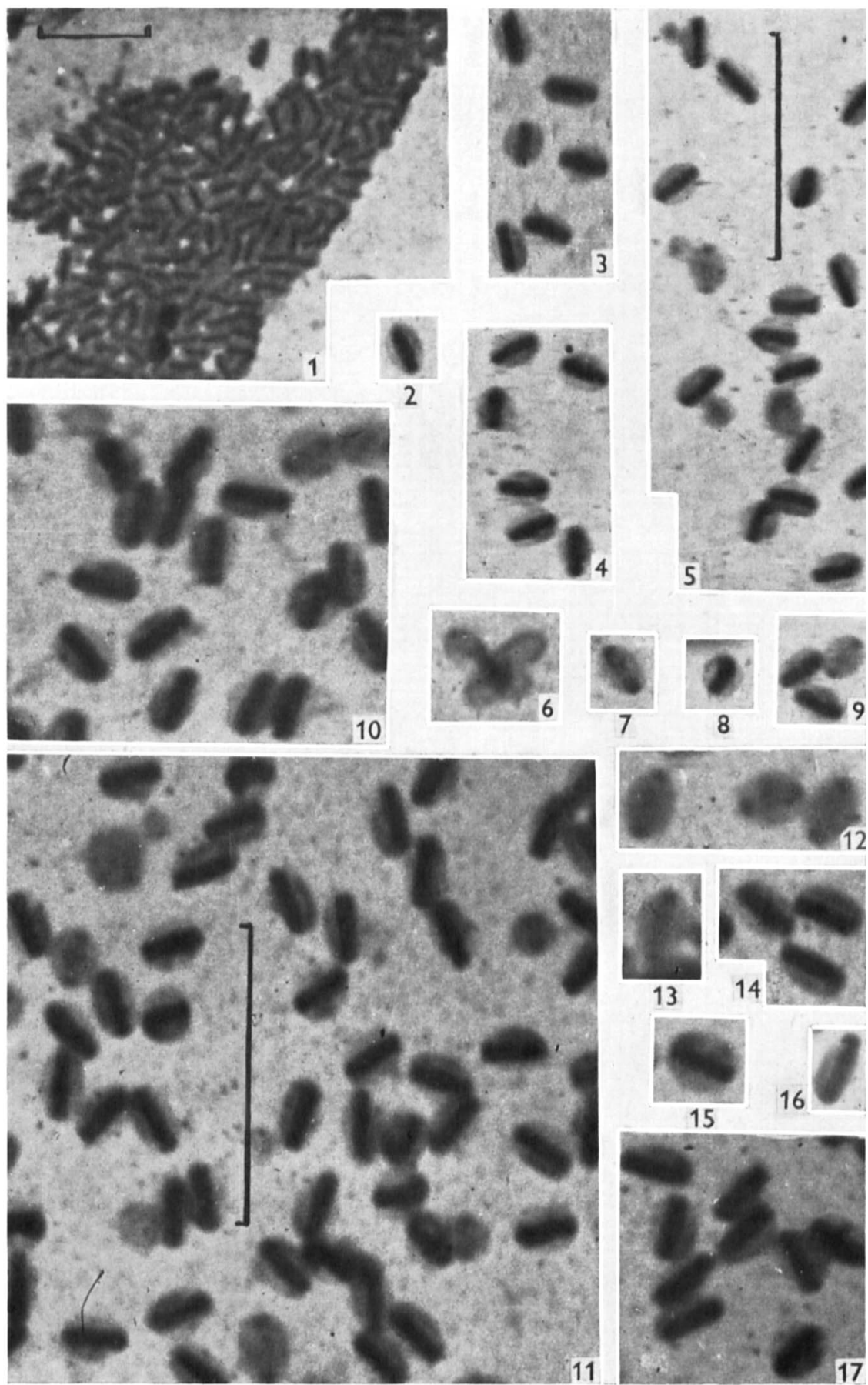

Figs. 1-17

Ch. Grégoire-Virus-like bodies in the house cricket. Plate 1 
be seen after treatment with alkali. Bergold's free virus particles have approximately the same size as the rod-shaped structures described here.

In the present material, the internal structures of the bodies were visible within their transparent envelope or sac without any treatment other than fixation with osmic acid. No liberation of dense rod-shaped particles from the sacs was observed. In addition, peculiarities of structure (circular areas of high density within some internal rods, and forms with two dense spherical polar areas visible within the envelope at the location of the rods) not mentioned in the descriptions of Bergold or of Steinhaus et al. suggest that the present bodies belong to a different type of organism with a complex internal organization. More detailed studies of these virus-like bodies and of various organs and tissues of insects from the same stock will show whether Gryllulus domesticus is a host species for a distinct disease of the group 'granuloses' or a 'healthy carrier' of a type of latent insect virus distinct from both the polyhedral and granular diseases.

I wish to express my thanks to Mr G. R. Wyatt, Virus Research Unit, Molteno Institute, Cambridge University, for several helpful suggestions while reading the manuscript.

\section{REFERENCES}

Bergold, G. (1948). Ueber die Kapselviruskrankheit. Z. Naturforsch. 3 B, 338.

Paillot, A. (1934). Un nouveau type de maladie à ultravirus chez les insectes. C.R. Acad. Sci., Paris, 198, 204.

Steinhaus, E. A., Hughes, M. \& W. Wasser, H. B. (1949). Demonstration of the granulosis virus of the variegated cutworm. J. Bact. 57, 219.

Steinhaus, E. A. \& Thompson, C. G. (1949). Granulosis disease in the Buckeye caterpillar Junonia coenia Huebner, Science, 110, 277.

\section{EXPLANATION OF PLATE}

Electron micrographs of bodies in thin films of haemolymph, fixed by immersion in $2 \%(w / v)$ osmic acid solutions, from adult specimens of Gryllulus domesticus. Magnification: the scales correspond to $1 \mu$. Figs. 2-9 have the same scale as fig. 5. Figs. 10-17 have the same scale as fig. 11.

Fig. 1. Agglutinated bodies in the plasma coagulum.

Figs. 2 and 15. Typical oval-shaped bodies.

Figs. 3-5, 10, 11 and 17. Bodies of different types described in the note, scattered in the plasma coagulym.

Fig. 6. A group of transparent envelopes or sacs without rod-shaped internal structure.

Figs. 7, 9, 12 and 13. Forms with dense circular polar areas, and in which the central rodshaped structure is not visible or only faintly outlined.

Figs. 9, 14 and 16. Bodies with clear envelopes or sacs mostly located on one side of the internal rod.

Fig. 8. Body with a curved internal rod. A similar body is seen in fig. 11 .

Fig. 16. Possible alignment of four dense areas within a rod-shaped internal structure.

(Received 3 April 1950) 